\title{
Plasticity after allogeneic hematopoietic stem cell transplantation
}

\author{
Alicia Rovó* and Alois Gratwohl \\ Hematology Department, University Hospital of Basel, \\ $\mathrm{CH}-4031$ Basel, Switzerland \\ ${ }^{*}$ Corresponding author \\ e-mail: RovoA@uhbs.ch
}

\begin{abstract}
The postulated almost unlimited potential of transplanted hematopoietic stem cells (HSCs) to transdifferentiate into cell types that do not belong to the hematopoietic system denotes a complete paradigm shift of the hierarchical hemopoietic tree. In several studies during the last few years, donor cells have been identified in almost all recipient tissues after allogeneic HSC transplantation (HSCT), supporting the theory that any failing organ could be accessible to regenerative cell therapy. However, the putative potential ability of the stem cells to cross beyond lineage barriers has been questioned by other studies which suggest that hematopoietic cells might fuse with non-hematopoietic cells and mimic the appearance of transdifferentiation. Proof that HSCs have preserved the capacity to transdifferentiate into other cell types remains to be demonstrated. In this review, we focus mainly on clinical studies addressing plasticity in humans who underwent allogeneic HSCT. We summarize the published data on non-hematopoietic chimerism, donor cell contribution to tissue repair, the controversies related to the methods used to detect donor-derived non-hematopoietic cells and the functional impact of this phenomenon in diverse specific target tissues and organs.
\end{abstract}

Keywords: fusion; hematopoietic stem cell transplantation; humans; microchimerism; organ repair; plasticity; transdifferentiation.

\section{Introduction}

The hematopoietic stem cell (HSC) is defined as a cell with extensive self-renewal, proliferation capacity, as well as the capacity to differentiate into progenitors of all blood cells: erythrocytes, granulocytes, monocytes, platelets, and all subtypes of lymphocytes. A single HSC has the ability to establish long-term hematopoiesis. This ability of long-term repopulation has been widely used for nearly four decades for hematopoietic stem cell transplantation (HSCT). After successful HSCT, a normal polyclonal hematopoiesis is reconstituted in the recipient.

There are an increasing number of studies providing evidence that regenerative cell-based therapies can lead to functional organ repair. As a result, there is a need for cells of the stem cell type to be able to be differentiated into mature organ-specific cells with complete functional capacity. Alternatively, human embryonic stem cells are pluripotential cells with the potential to differentiate into any cell type in the presence of adequate stimulating factors and suitable environments. So far, the clinical use of embryonic stem cells for regenerative medicine is hampered by a number of technical, political and ethical barriers. Consequently, there is a desire for other types of human stem cells capable of differentiating and proliferating into defined mature cells. HSCs appear to be an ideal candidate, as they have a great capacity to proliferate and are easily obtained. Proof that HSCs have preserved the capacity to transdifferentiate into other cell types remains to be demonstrated.

Recently, a series of exciting reports has placed marrow-derived stem cells as the first candidate for such use. In vitro (Reyes et al., 2001; Collas, 2003) and animal studies (Gussoni et al., 1999; Brazelton et al., 2000; Alison et al., 2001, 2003; Krause et al., 2001; Akiyama et al., 2002; LaBarge and Blau, 2002; Masuya et al., 2003; Doyonnas et al., 2004; Palermo et al., 2005) postulated the nearly unlimited potential of stem cells. Results from studies performed in mice following a rigorous study design provided the reference and the context for further investigation in humans. Subsequently, many studies performed in humans have identified donor cells in almost all recipient tissues, supporting the theory that any failing organ could be accessible to regenerative cell therapy (Figure 1) (Alison et al., 2000; Korbling et al., 2002; Tran et al., 2003; Cogle et al., 2004; Spyridonidis et al., 2004).

The putative potential ability of stem cells to cross beyond lineage barriers (Anderson et al., 2001; Blau et al., 2001) has been denominated 'plasticity' and it refers specifically to transdifferentiation. However, this concept of plasticity has been questioned. Some studies did suggest that stem cells might fuse with other cells and mimic the appearance of differentiation (Vassilopoulos et al., 2003; Wang et al., 2003). Likewise, other studies postulated the presence of fetomaternal microchimerism as the explanation for this finding (Evans et al., 1999; Reed et al., 2007).

The disparity of results, the difference in the methods used to investigate transdifferentiation or plasticity, and thus also the difficulties in reproducibility, converted the initial excitement into a more skeptical position. Many investigators called for caution in the interpretation of the results of studies. Today, deep uncertainty remains regarding the plasticity of HSCs. The argument in favor 


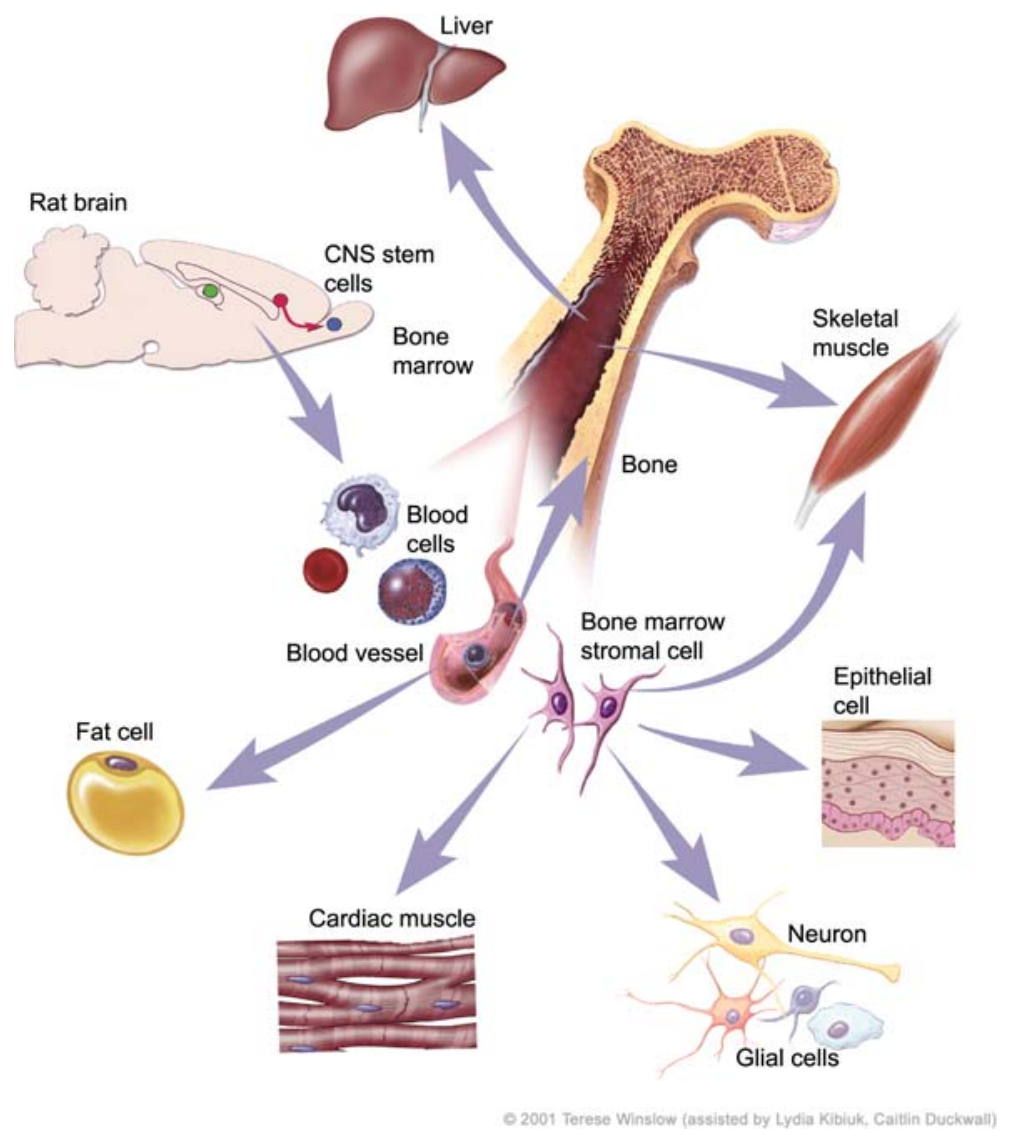

Figure 1 Potential contribution of bone marrow-derived cells to organ repair. c) Terese Winslow, reproduced with permission.

of plasticity of HSCs is supported by the plethora of publications and the extensive debate in the community as reflected in the media.

In this review, we focus mainly on clinical studies addressing plasticity in humans who underwent allogeneic HSCT. Clinical allogeneic HSCT provides a unique opportunity to assess the contribution of transplanted healthy allogeneic donor cells for organ repair. Because most patients are pretreated with intensive chemo- and radiotherapy, the so-called conditioning, the recipient organs are consequently in high need of repair. If donor cells could contribute to such regenerative organ repair and thereby should be confirmed. We summarize the published evidence of donor cell contribution to tissue repair, the methods used for its detection and the functional impact in different specific target organs. Postulated mechanisms of the donor-derived stem cells in organ repair are further addressed.

\section{Mechanisms for non-hematopoietic mixed chimerism after allogeneic HSCT}

Mixed chimerism is a term used in transplantation medicine to define a cellular phenomenon, where the recipient of a transplant has cells of his own as well as from the organ donor. In allogeneic HSCT, a mixed chimerism is usually defined as a situation in which the hematopoietic cells belong in part to the recipient and, for the other part, to the donor (Figure 2). The term non-hematopoietic mixed chimerism can be used post-allogeneic HSCT, where non-hematopoietic cells in the recipient can be of both recipient and donor origin. There are several possible mechanisms that could lead to a non-hematopoietic mixed chimerism; these are plasticity, transdifferentiation, fusion and fetomaternal microchimerism.

\section{Plasticity and transdifferentiation}

The ability of the HSCs to transdifferentiate into cell types that do not belong to the hematopoietic system denotes a complete paradigm shift of the hierarchical hematopoietic tree. The differentiation of HSCs into muscle can be acceptable, considering that blood cells and muscle cells belong to the same germ layer, the mesoderm (Peault et al., 2002). This process might even be bidirectional. Crossing barriers within the same germ layer is referred to as plasticity. In contrast, HSCs differentiating into intestinal epithelial cells would represent crossing of the embryo germ layer barrier (mesoderm to endoderm) and is referred to as a transdifferentiation phenomenon (Figure 3). Transdifferentiation in vitro involves a signal which reprograms the genes expression profile in the nucleus (Reyes et al., 2001; Tada et al., 2001; Collas, 2003). In this process, regulatory factors are actively taken up by the nucleus, inciting the cells to express molecules and functions by downregulating the expressed genes in the original cells. 

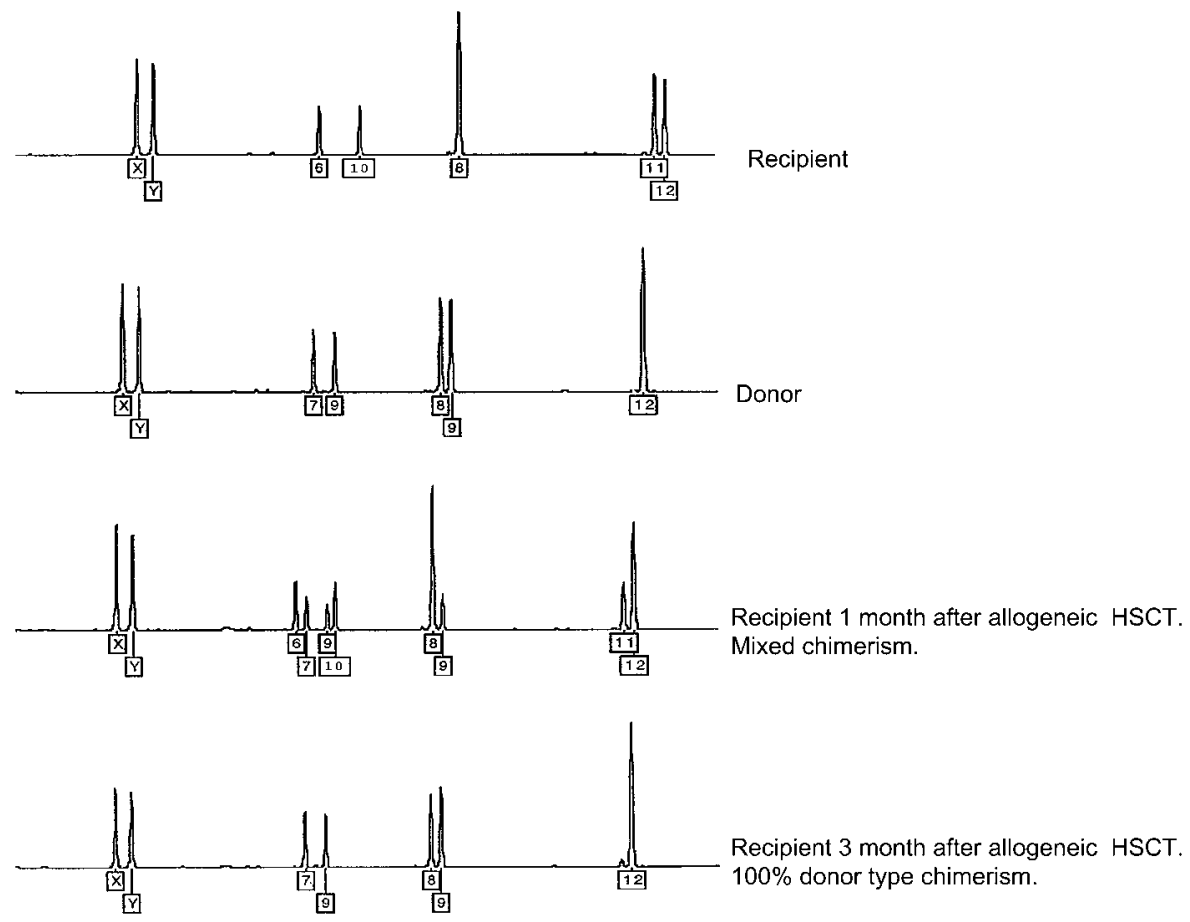

Figure 2 Chimerism analysis after allogeneic hematopoietic stem cell transplantation (HSCT).

Chimerism of peripheral blood by PCR-based DNA amplification of nine different short tandem repeat (STR) loci and the Amelogenin locus, which allows discriminating the $X$ and $Y$ chromosomes. For PCR amplification of the STR, the AmpFIProfiler ${ }^{\text {TM }}$ PCR Amplification Kit (PE Applied Biosystems, Foster City, USA) was used. PCR products were separated by capillary electrophoresis on the ABI Prism 310 Genetic Analyzer (PE Applied Biosystems) and fragment sizes were analyzed with the GeneScan ${ }^{\mathrm{TM}}$ software. Informative peaks, i.e., peaks which are different between recipient and donor, were used for calculation of the donor contribution. The peak integral served for the relative quantification of the product.

Embryonic germ layer Differentiation of human tissues

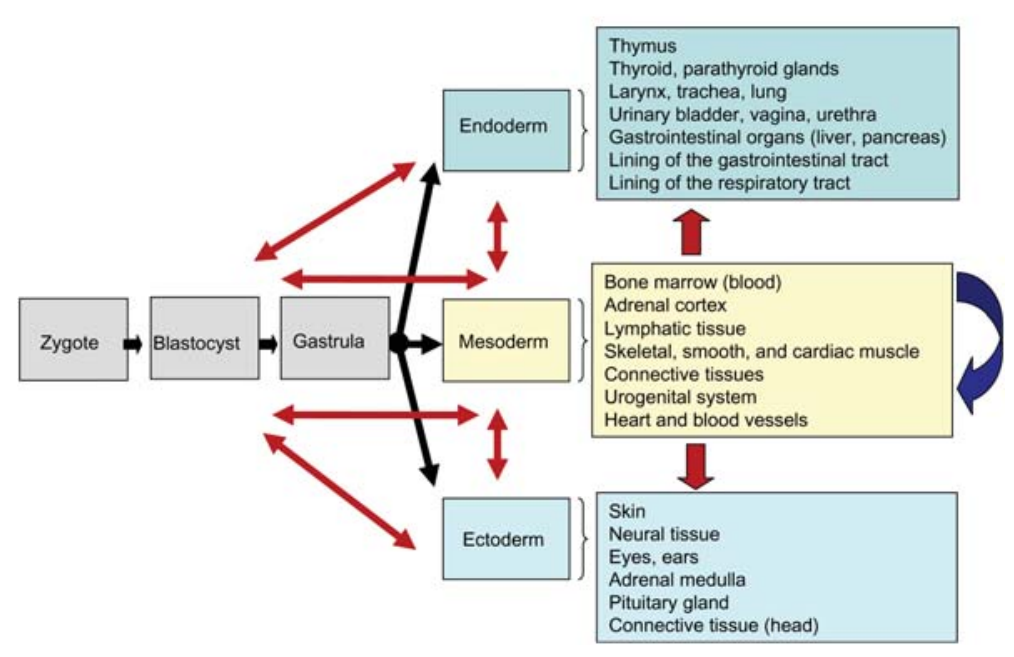

Figure 3 Schematic representation of adult mammals' embryonic development (black arrows). Plasticity within and across germ layer lines, hypothetical pathway (red and blue arrows).

The molecular basis of transdifferentiation, dedifferentiation and stem cell plasticity may be explained by aberrant processes during cell differentiation. Hence, at some stages of cell differentiation or metabolic switch, cells undergo profound changes in gene expression. These events are associated with complex modifications of chromosomal components and nuclear structures, going from simple covalent modification of DNA and chromatin up to topological reorganization of chromosomes and genes in the nucleus. Epigenomic levels of gene regulation usually contribute to the stability and heritability of transcription programs. When damage of the epigenomic components occurs, a determined cellular program can result to skewed development. These aberrant processes 
can be detected by gene expression profiles, as well as by analysis of epigenetic modification of DNA and histone proteins of the involved cells (Lanzuolo and Orlando, 2007; Li et al., 2007; Rizzino, 2007). In mice and in humans, mechanisms regulating self-renewal and cell fate decisions may be approached by global gene expression profiles of HSCs and cells at later stages of the hematopoietic hierarchy. Indeed, murine and human HSCs share a number of expressed gene products, which define key conserved regulatory pathways in this developmental system. Moreover, in the mouse, part of the genetic program used by HSCs is shared with embryonic and neural stem cells. This overlapping gene product represents a molecular signature of stem cells (Ivanova et al., 2002; Ramalho-Santos et al., 2002).

Regarding the terminology there is no real consensus about how to denominate this phenomenon. Several authors do not differentiate plasticity from transdifferentiation and use both terms interchangeably, whereas other authors prefer to omit the use of the term plasticity to minimize confusion and use transdifferentiation to make the distinction. The term plasticity has been widely referred to as the capacity of adult stem cells to cross lineage barriers.

Methodological limitation has been pointed out as the most difficult aspect for the interpretation of the results of plasticity and transdifferentiation. The following criteria should be fulfilled to demonstrate these phenomenon in vivo (Anderson et al., 2001): the donor population should be prospectively isolated and transplanted without intervening culture manipulations, the transplanted stem cells should give rise to robust and sustained regeneration of the target tissues; the converted cells need to have not only the anticipated anatomical and molecular phenotype, but also the functional characteristics. In addition, transdifferentiated stem cells should have normal chromosome contents. Finally, the presence of contaminated cells should always be considered as confounding factors and should be systematically ruled out.

\section{Fusion}

Cell fusion could be a mechanism that explains part of the results of transdifferentiation of HSCs into liver cells (Figure 4) (Grompe, 2003), cardiomyocytes and neurons. This mechanism seems to be, in part, responsible for bone marrow-derived stem cell repair of damaged tissue (Medvinsky and Smith, 2003).

In a mice model, Alvarez-Dolado and colleagues, using a simple method based on Cre/lox recombination (a technique extensively used to conditionally turn on or off gene expression in specific cell types or tissues) to detect cell fusion events, demonstrated that bone marrow-derived cells fuse spontaneously with neural progenitors in vitro. Furthermore, bone marrow-derived cells fuse in vivo with hepatocytes in liver, Purkinje neurons in the brain and cardiac muscle in the heart, resulting in the formation of multinucleated cells. No evidence of trans-
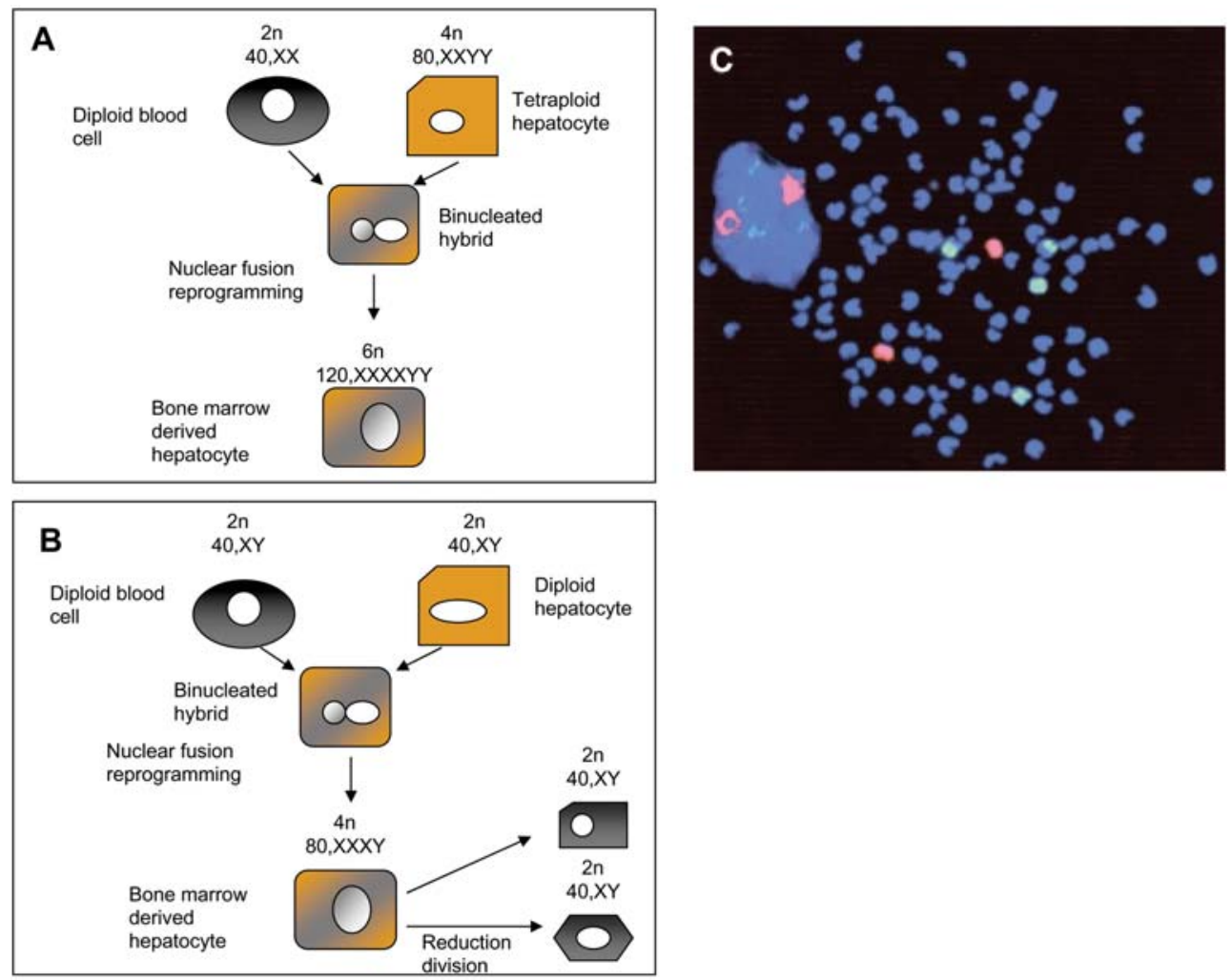

Figure 4 Cell fusion schematic.

(A) Fusion of a diploid blood cell and tetraploid hepatocyte, resulting in a binucleated hybrid, which then becomes a hexaploid fusion hepatocyte. (B) Fusion of diploid blood cell and diploid hepatocyte to form a tetraploid fusion hepatocyte. This cell can undergo a reduction division and become diploid again. (C) FISH analysis of a hexaploid fusion hepatocyte that has two $\mathrm{Y}$ (pink) and four $\mathrm{X}$ (green) chromosomes. Adapted from Grompe (2003) (@Thieme, reproduced with permission). 
differentiation without cell fusion has been observed in these tissues (Alvarez-Dolado et al., 2003). Terada et al. (2002) demonstrated that mice bone marrow cells can fuse spontaneously with embryonic stem cells in vitro cultures that contain interleukin-3. Additionally, other studies reported that spontaneously fused bone marrow cells can subsequently adopt the phenotype of the recipient cells, a phenomena which, without detailed genetic analysis, might be interpreted as 'dedifferentiation' or transdifferentiation (Ying et al., 2002).

\section{Fetomaternal microchimerism}

Microchimerism is defined as the presence of a small number of cells genetically distinct from those of the host. The most common form is fetomaternal microchimerism, where cells from a fetus are found in the mother. Fetal cells have been documented to persist in maternal circulation and tissues for as long as 38 years (Bianchi et al., 1996; Evans et al., 1999). Stem cells or tissues obtained from a woman who has been pregnant are likely to contain cells of her fetuses. This chimeric cell population may have different biological properties as compared to adult stem cells or organ cells obtained from a nulliparous woman or from a man (Bianchi and Fisk, 2007). Fetomaternal microchimerism can also develop during abortion. Using polymerase chain reaction to measure Y-chromosomal sequences, up to 500000 nucleated fetal cells enter a woman's circulation following routine surgical abortion (Bianchi et al., 2001). For plasticity evaluation, many of the studies used Y-fluorescence in situ hybridization (Y-FISH) as a method to track donor HSC-derived cells in sex-mismatch transplantation. In females with previous pregnancies or abortions with a male fetus, the potential presence of fetomaternal microchimerism could be a confounding factor in positive results. Indeed, in a carefully conducted single-center study, data did fit with this hypothesis demonstrating a potential impact on clinical HSCT. Siblings born after the recipients should have fetomaternal and transmaternal sibling cell trafficking and tolerization of the donor. Firstborn recipients should therefore experience less acute graft versus host disease, incidence of relapses and transplant related mortality (Bucher et al., 2007) Moreover, microchimerism has also been demonstrated after blood transfusions in severely immunocompromised patients who suffered trauma (Reed et al., 2007).

\section{Evidence of HSC contribution to tissue repair}

\section{HSC differentiation in the central nervous system}

Bone marrow cells have been reported to differentiate into neurons and astrocytes when transplanted into normal and ischemic brain (Bjornson et al., 1999; Eglitis et al., 1999; Woodbury et al., 2000). After intravenous application of bone marrow fraction into terminally $\mathrm{X}$-irradiated rats, cells with neuronal phenotypes derived from the injected bone marrow can be found in the brain (Brazelton et al., 2000; Mezey et al., 2000). In humans, Cogle et al. (2004) demonstrated that HSCs can transdifferentiate into neurons, astrocytes and microglia. They examined autopsy brain specimens from three sex-mismatched female bone marrow transplantation patients, a female control and a male control. They performed immunohistochemistry, FISH and tissue analysis to look for multilineage, donor-derived neurogenesis. In all three patients, a $\mathrm{Y}$ chromosome was present in the hippocampal cells up to 6 years post-transplant. Transgender neurons accounted for $1 \%$ of all neurons. The fact that only one $\mathrm{X}$ chromosome was present excluded the hypothesis of cell fusion as an explanation for this phenomenon. Moreover, transgender astrocytes and microglia made up $1-2 \%$ of all glial cells (Cogle et al., 2004).

Crain et al. (2005) examined paraffin sections from female patients who had received bone marrow transplants from male donors. Y-chromosomes were labeled using autoradiography and FISH. Neurons and astrocytes were identified histologically and immunohistochemically in neocortex, hippocampus, striatum and cerebellum. However, most Y-chromosome labeled cells in gray and white matter appeared to be glia. The female patients in this study had received either bone marrow or stem cell $\left(\mathrm{CD} 34^{+}\right.$-enriched) transplants from their brother. Genotyping studies of one patient, her brother, and her son ruled out the possibility of fetomaternal microchimerism. Overall, the numbers of labeled cells (including neurons) were approximately 10-fold lower than in rodent studies (2-5/10 000 vs. $50 / 10000)$ (Brazelton et al., 2000; Mezey et al., 2000). Furthermore, 3 out of 4 required criteria to demonstrate plasticity of adult stem cells were fulfilled. The positive findings could not be explained by cell fusion.

Other groups have shown that Purkinje neurons from the cerebellum can fuse with bone marrow-derived cells in both mouse and human beings (Alvarez-Dolado et al., 2003; Weimann et al., 2003a,b). Weimann et al. (2003a) showed, in cerebella sections screened for Y-chromosomes, that the total frequency of male bone marrow contribution to female Purkinje cells approximated $0.1 \%$. Despite the fact that Purkinje neurons are no longer generated after birth, in humans, bone marrow cells could contribute to the formation of new neurons in adults, meaning in fact that two mechanisms of neuronal development have to be envisioned. Cells from bone marrow could fuse with damaged neuronal cells, providing them with an undamaged nucleus. Alternatively, cells of donors could undergo a change in their cell fate and replenish damaged tissues by converting their phenotype into the cell type needed in the tissue to which they migrated.

\section{HSC to skin and endothelium}

Experimentally, it has been demonstrated that bone marrow-derived cells contribute to epithelial engraftment during wound healing (Borue et al., 2004). Murata et al. (2007) evaluated 18 female patients who underwent HSCT from a male donor, in whom a skin rash led to a skin biopsy. Acute Graf-versus-Host Disease (GvHD) was confirmed in 13 of them. Donor-derived keratinocytes, characterized as CD45-, AE1/AE3 ${ }^{+}$and $\mathrm{XY}$ cells, were found in 12 patients with an average of $5.5 \%$ (range 1.6-7.8\%). Donor-derived endothelial cells, characterized as $\mathrm{CD}^{-} 1^{+}, \mathrm{CD} 45^{-}$and $\mathrm{XY}$ cells were found in skin biopsies of 13 patients (mean 4.3\%; range 2.2-9.4\%). 
These data were in accordance with a previously published study (Jiang et al., 2004), in which a mean of $2 \%$ donor-derived endothelial cells were reported in the skin and gut of human transplant recipients. In this last study, 3 out of 12 patients had GvHD and all three showed donor-derived endothelial cells. In both studies, there was a close association between chimeric cells and pathologically proven acute GvHD, suggesting the contribution of donor-derived cells in endothelial repair of GvHD-induced lesions.

Human tissue samples from the aorta and peripheral arteries were obtained at autopsy in the case of a patient who underwent peripheral HSCT for acute radiation syndrome. Endothelial cells, characterized by von Willebrand factor immunostaining, were isolated and subjected to FISH analysis using $\mathrm{X}$ - and Y-chromosome-specific probes to examine neoendothelialization by donor cells. In the aorta, almost $25 \%$ of all endothelial cells were replaced by donor-origin endothelial cells. In the peripheral arteries a similar, less extensive phenomenon was observed (Suzuki et al., 2003).

\section{HSC to hair follicles and fingernails}

Transient hair injury and as a result alopecia is evident in most patients after HSCT, mainly when intensive conditioning is applied. We assessed chimerism quantifications on DNA extracted from hair follicles in a large cohort of 115 patients after HSCT. Despite being an organ with high need for repair, all hair follicles showed 100\% recipient alleles and were therefore fully of recipient type (Rovo et al., 2005; Seifert et al., 2005). Recently, these results were confirmed by Hong et al. Using the same short tandem repeat (STR) method, they established that hair follicles were $100 \%$ recipient type in all 29 evaluated patients and suggested that after successful allogeneic HSCT, the hair follicle is a reliable source of the recipient's origin when pre-transplant DNA fingerprinting from donor and recipient is not available (Hong et al., 2007).

Hair and nail have similar biologic features; they share the same origin from ectoderm and have a lifelong, continuous regeneration. We would therefore expect similar results in chimerism performed from fingernails compared to hair follicle after allogeneic HSCT. However, a recent publication applying the same STR method of detection in recipients' fingernails showed opposite results. In 9 out of 21 recipients, coexistence of donor pattern in a range from $8.9 \%$ to $72.9 \%$ was identified. GvHD was not associated with this finding. The authors interpreted this result as stable donor contribution, despite the fact that they were unable to track individual cells with this method (Imanishi et al., 2007).

\section{HSC to liver}

Theise and colleagues showed that $4-43 \%$ of the hepatocytes and $4-38 \%$ of the cholangiocytes in liver biopsy and in autopsy material from two female patients after HSCT were of donor bone marrow cell origin (Theise et al., 2000). Shortly afterward, Korbling and colleagues reported that stem cells in mobilized peripheral blood and marrow showed plasticity in vivo. They found that $2-7 \%$ of hepatocytes and epithelial cells of skin and gut were of donor origin 13-867 days after transplantation (Korbling et al., 2002).

\section{HSC to buccal mucosa}

STRs are markers which are currently used in forensic medicine to demonstrate diversity in tissue derived from different individuals. The same method is now widely applied to demonstrate hematopoietic chimerism after allogeneic HSCT. This method is robust, reproducible, provides good sensitivity, and is not dependent on a sexmismatch between recipient and donor (Thiede et al., 1999, 2001, 2004; Thiede, 2004). The oral mucosa represents an attractive source of suitable material for DNAbased assessment of hematopoietic chimerism after HSCT, because after successful HSCT, buccal mucosa is supposed to be of recipient, and hematopoietic cells from donor origin. This is a particularly useful method when the DNA profile from the donor is not available for chimerism evaluation. Cheek mucosa collected samples using both mouthwashes as well as buccal swab show a mixed chimerism with $74 \%$ (range 16-95\%) and $21 \%$ (5-63\%) of donor type, respectively. These results are due to blood cell contamination (Endler et al., 1999; Thiede et al., 2000). Beyond these results on buccal mucosa, Tran and colleagues (2003) evaluated whether bone marrow donor cells could colonize an epithelial tissue and transdifferentiate there without fusion. They tracked donor-derived buccal mucosa cells using an anticytokeratin 13 antibody to detect mucosal cells and a FISH method to identify male donor origin of buccal epithelial cells in cheek scrapings obtained from female patients. In total, there were five female patients who had received either bone marrow or mobilized peripheral blood progenitor cells (enriched in CD34 ${ }^{+}$cells) for HSCT from male donors 4-6 years before. All female recipients had $Y$ chromosome positive buccal cells $(0.8-12.7 \%)$ without evidence of cell fusion. Because in more than 9700 cells studied, only one XXXY-positive cell (0.01\%) and one $X X Y$ cell $(0.01 \%)$ was detected, both of them could be the result of $X Y$ cell fusion with an $X X$ cell.

\section{HSC to gastrointestinal mucosa}

Meignin and colleagues performed gastrointestinal biopsy in six female patients with acute GvHD within 13-33 days after allogeneic HSCT (Meignin et al., 2004). Using stringent criteria, no donor-derived epithelial cells could be found. Their results differ from previously published data on the human digestive tract after HSCT, where epithelial cells of donor origin were regularly found at a low rate (Brittan et al., 2002; Korbling et al., 2002; Okamoto et al., 2002). These earlier studies were performed in sex-mismatched transplantation but with different technical conditions used for tissue preparation. Meignin et al. (2004) used the XY FISH method, which allows for the elimination of most non-specific signals, large-spectrum fluorescence. They also combined FISH and immunostaining results on the same tissue section to avoid serial consecutive sections, and in the same way localization bias.

Spyridonidis and colleagues (Spyridonidis et al., 2004) demonstrated with a very comprehensive and rigorous 
method that chimerism of colon epithelium is a real phenomenon occurring constantly after human HSCT. Colon snap-frozen biopsies were performed in eight female patients with clinical signs of gastrointestinal GvHD who underwent a sex-mismatched allogeneic HSCT. Using confocal microscopy and 3D analysis on single sections of biopsies, and using triple staining with donor-specific $(Y)$, epithelial-specific (cytokeratin) and hematopoieticspecific (CD45) markers, they detected $\mathrm{Y}^{+}$/cytokeratin ${ }^{+} /$ CD45-, donor-derived epithelial cells in all patients. The mean of donor-derived cells was $0.18 \%$ of the overall colon epithelial cells, with higher numbers found in the sections with histologically documented tissue damage (mean $0.22 \%$; six patients). They ruled out fusion as the underlying mechanism, combining cytokeratin staining with YX-FISH quantitative method. Moreover, the majority of the intraepithelial chimeric events found were due to donor type $\mathrm{Y}^{+} / \mathrm{CD} 45^{+}$intraepithelial lymphocytes which were in close contact with epithelial tissue. The authors warn about the risk of falsely interpreting these donor lymphocytes as donor-derived epithelial cells if the 3D structure of the tissue is not considered in combination with the hematopoietic markers.

\section{HSC to endometrium}

The endometrium is a dynamic, cyclically regenerating tissue, and therefore represents a unique model of physiological angiogenesis in adults. Mints et al. (2007) evaluated whether newly formed male endothelial cells in mice and humans could be detected in the endometrial blood vessels of female recipients after HSCT from a male donor. They performed endometrial biopsies after cesarean section in a patient treated previously with nonmyeloablative allogeneic HSCT, and in two controls. Endothelial cells were detected by immunohistochemistry using CD34 and VEGFR2 antibodies, and donor cell origin by FISH analysis. Chimerism was analyzed using real-time PCR. The same experiment was also performed in an animal model. They found that at the time of the cesarean section of the transplanted female patient, an average of $14 \%$ of the endometrial endothelial cells were donor-derived. In a biopsy repeated 1 year later, the donor-derived endothelial cells were still $10 \%$. In contrast, none of two non-transplanted females demonstrated a sex-mismatch in endometria at cesarean section. In samples from female mice, harvested 40 days after HSCT, a $6 \%$ average of donor-derived endothelial cells was detected (Mints et al., 2007).

\section{HSC to lung}

After lung injury and damage to the alveolar epithelium, the underlying basement membranes become exposed. Proliferation of type II pneumocytes and their differentiation into type I pneumocytes have been considered to be the mechanism by which repopulation of the alveolar epithelium occurs. Different groups showed that, as in animal models, the epithelium of the adult human lung has the capacity to renew itself, using cell recruitment from extrinsic sources. Several studies evaluated lung specimens from surgical resection or autopsy samples from female patients who had received an HSCT from a male donor. Using a combination of immunochemistry and $\mathrm{FISH}$ technique, the presence of cells from HSC donor origin has been shown by all groups. However, the occurrence of fusion was not systematically ruled out (Suratt et al., 2003; Mattsson et al., 2004; Albera et al., 2005; Loebinger and Janes, 2007).

\section{HSC to heart and muscle}

Attempts to repair myocardial infarcts by transplanting cardiomyocytes or skeletal myoblasts have failed to reconstitute healthy myocardium and coronary vessels integrated structurally and functionally with the remaining viable portion of the ventricular wall. Orlic and colleagues demonstrated in a mouse model that bone marrow cells injected in the border zone of acute infarcts Lin2 ckitPOS from syngeneic animals differentiated into myocytes and vascular structures, ameliorating the function of the infarcted heart (Orlic et al., 2001). In humans, several studies suggest improvement in cardiac function when autologous bone marrow or peripheral stem cell is injected directly into damaged myocardium. In these studies, it was not possible to assess whether the improved outcomes did result from generation of HSCderived myocytes or were due to ancillary effects (Stamm et al., 2003, 2004; Tse et al., 2003; Heil et al., 2004; Mathur and Martin, 2004; Wollert et al., 2004; Drexler et al., 2006; Meyer et al., 2006; Griesel et al., 2007; Sohn et al., 2007). Some authors suggested that HSC might promote vascular growth by their paracrine effects and not by incorporation into the wall of growing vessels. There are almost no data on the contribution of allogeneic HSCT to myocardial repair in humans.

Growth and repair of skeletal muscle is normally mediated by the satellite cells that surround muscle fibers. During muscle regeneration, however, the number of myogenic precursors exceeds that of resident satellite cells, implying migration or recruitment of undifferentiated progenitors from other sources. In animal models, the injection of bone marrow into the circulation contributes to muscle enhancement in response to increased muscle activity. These results indicate that bone marrow-derived cells contribute to myofibers in response to physiologic stress encountered by healthy organisms throughout life (Ferrari et al., 1998; Palermo et al., 2005). In humans, Gussoni et al. (2002) reported on the examination of muscle biopsies from a patient who received bone marrow transplantation at 1 year of age for $\mathrm{X}$-linked severe combined immune deficiency and who was diagnosed with Duchenne muscular dystrophy at the age of 12 years. Analysis of muscle biopsies, performed at the time the Duchenne muscular dystrophy was already diagnosed, revealed the presence of donor nuclei within a small number of muscle myofibers (0.5-0.9\%), showing the ability of exogenous human bone marrow cells to fuse into skeletal muscle and persist up to 13 years after HSCT (Gussoni et al., 2002).

\section{Cancer originating from donor HSC}

HSCT is now successfully utilized in the treatment of malignant and non-malignant diseases resulting in a growing cohort of long-term survivors. The development 
of subsequent malignant neoplasms is one of the major long-term adverse complications observed in these patients. Usually, these secondary solid cancers are of recipient type. However, the conjecture about the cell origin of the non-hematopoietic tissues after HSCT has led to a closely related theory that cancer could also be donor-derived. So far, the evidence of this hypothesis is extremely scarce and only further systematic searches for donor-derived stem cells in the newly diagnosed solid tumor in long-term survivors after HSCT will shed some light on this controversial theory (Houghton et al., 2004; Alison et al., 2006; Arai et al., 2006; Avital et al., 2007; Soldini et al., 2008).

\section{Are the current results inaccurate by over-interpretation? Evaluation of the methods used to detect non-hematopoietic mixed chimerism}

Most of the controversies on plasticity are related to the methods used to detect donor-derived non-hematopoietic cells in various tissues and organs. To demonstrate HSC plasticity or transdifferentiation, all the proposed criteria have to be fulfilled (Anderson et al., 2001). The relevant cell type must be unequivocally identified using immunohistochemistry, immunofluorescence and functional assay. A combination of more accurate methods, including $3 D$ to track cells using a more specific approach, should be systematically applied (Spyridonidis et al., 2004; Murata et al., 2007). To exclude cell fusion (Alison et al., 2004), the karyotype of newly generated cells needs to be detected using, e.g., the method of FISH which allows counting of the number of chromosomes and tags specific chromosomes with unique fluorescent dyes (Figure 4C). Karyotyping with FISH distinguishes between cellular transdifferentiation (diploid, donor genotype) and cell fusion (tetraploid or greater, mixed donor, and recipient genotypes). The proof for evaluating whether cells belonging to the donor or the recipient is usually based on genetic differences. In most cases, an in situ technique is used to detect the sex difference. Unfortunately, in humans, only patients who have a donor from the opposite sex will be suitable for this analysis.

The DNA-based STR method, used to reveal donorderived HSC chimerism, has an evident limitation in the case of mixed non-hematopoietic chimerism. The result refers to the presence of donor type cells but does not provide further information regarding cell identity. In such a case, the interpretation should be posited with extreme caution. The most usual pitfall is due to the contamination of the material by hematopoietic donor cells, such as lymphocytes, leading to a result that can be misinterpreted as donor-derived cell plasticity. Indeed, in our study on male spermatogenesis after HSCT (Rovo et al., 2006), we were looking for chimerism in sperm samples when spermatozoa was detected in the microscopic fresh analysis. STR analysis was performed from six frozen sperm samples. The results showed a mixed chimerism in all patients with a percentage of donor contribution between $20 \%$ and $40 \%$ (data not published).
These provocative results were highly questionable. Consequently, we systematically reviewed the cytological protocols of the sperm samples provided by the andrology laboratory. A very low rate of lymphocyte contamination has been systematically described, explaining the outcome. Positive results published recently, in which STR was applied as a detection method for mixed nonhematopoietic chimerism in fingernail, revived the debate. The authors depicted between $8.9 \%$ and $72.9 \%$ donor type DNA obtained from fingernails, and concluded that this represents a stable contribution of HSC donor cells to fingernail production after HSCT. They rejected the possibility of contamination by donor type hematopoietic cells, even though they used an indirect method to demonstrate absence of lymphocytes in fingernails in another group of patients (Imanishi et al., 2007).

\section{Where are we, where are we going?}

Based on numerous studies in allogeneic HSCT (Table 1), there is now data to support the concept that donorderived cells can be found in various tissues and organs of the recipients after successful transplantation. In some cases, it seems that plasticity and transdifferentiation plays a determinant role. However, other phenomena, such as cell fusion, can lead to conflicting results. Over the last few years, we have learnt much about technical drawbacks leading to misinterpretation of the results. We know now which stringent criteria have to be applied to prove cell plasticity. There is evidence that the low frequency of HSC-derived non-hematopoietic cells showed in many organs seems to be too low to be of therapeutic relevance. Overall, plasticity after allogeneic HSCT seems to be an erratic event, without a specific pattern for contributing factors. Moreover, there are no hints on how to influence the degree of chimerism on organ repair, and so far, long-term repeated follow-up studies are lacking. We can conclude that unmanipulated HSCs are therefore unlikely to provide organ repair beyond hematopoiesis either from adult bone marrow or mobilized peripheral stem cells. Whether other organ specific stem cell progenitors circulating in blood constitute a backup to maintain homeostasis in self-renewal and a repair of different tissues or not should be addressed (Hennessy et al., 2004). This review permits the conclusion that there is a need for systematic cross-sectional and longitudinal observational studies, which should lead to defining factors associated with the degree of chimerism. Different potential scenarios can be drawn for the future: (1) we will be able to identify and influence factors associated with chimerism, and hence we will find tools to induce chimerism or influence homing; (2) there will be a necessity for in vitro manipulation of HSCs prior to application to induce target-specific orientation or homing; and finally, (3) HSCT would no longer be needed, as the possibility of reprogramming cells will obviate the need for non-specific stem cell induced organ repair (Takahashi et al., 2007). 


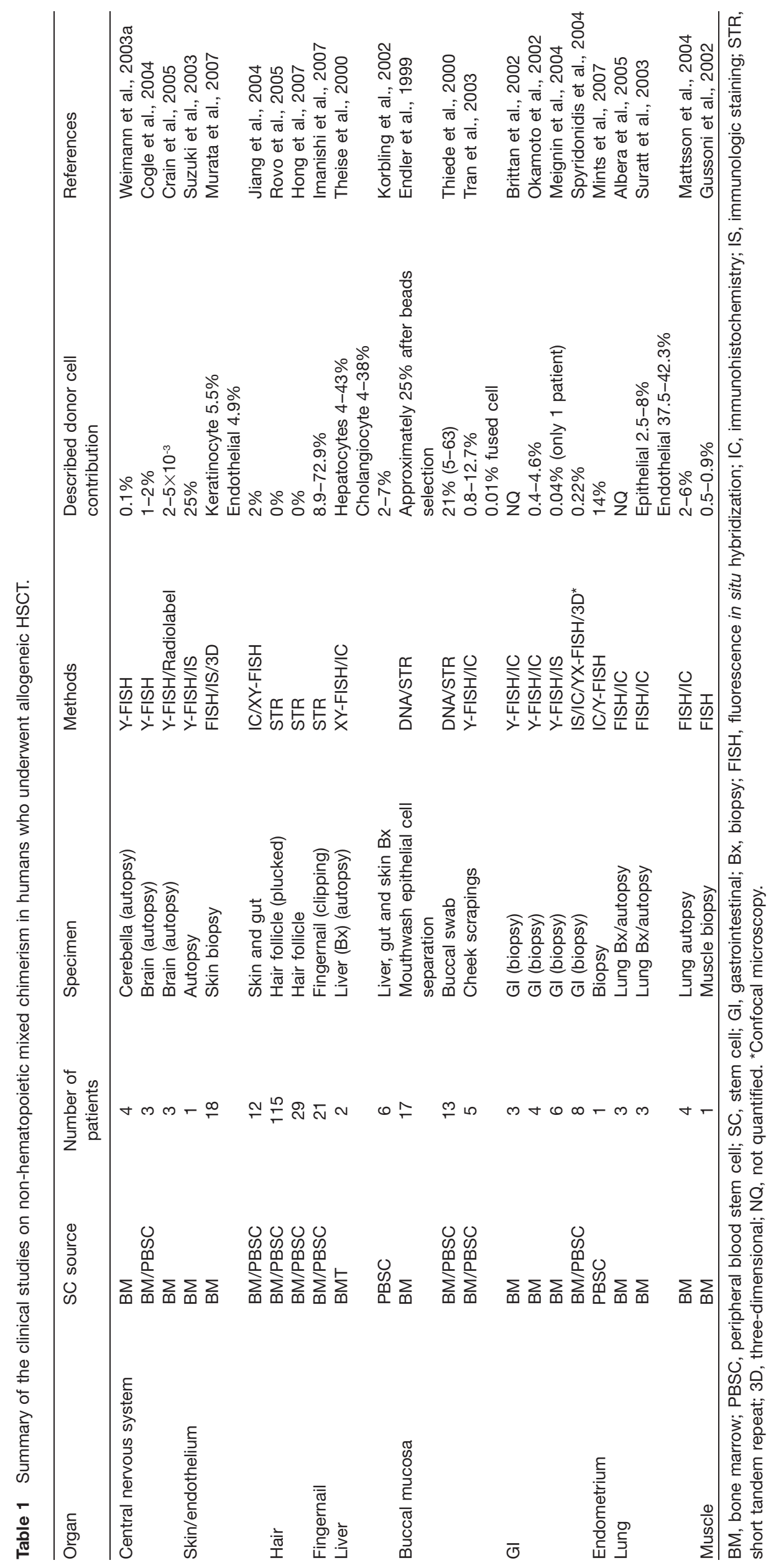




\section{Acknowledgments}

This study was supported by a grant from the Swiss National Research Foundation 3200 BO-118176 and the Helmut Horten Foundation.

\section{References}

Akiyama, Y., Radtke, C., Honmou, O., and Kocsis, J.D. (2002). Remyelination of the spinal cord following intravenous delivery of bone marrow cells. Glia 39, 229-236.

Albera, C., Polak, J.M., Janes, S., Griffiths, M.J., Alison, M.R., Wright, N.A., Navaratnarasah, S., Poulsom, R., Jeffery, R., Fisher, C., et al. (2005). Repopulation of human pulmonary epithelium by bone marrow cells: a potential means to promote repair. Tissue Eng. 11, 1115-1121.

Alison, M.R., Poulsom, R., Jeffery, R., Dhillon, A.P., Quaglia, A., Jacob, J., Novelli, M., Prentice, G., Williamson, J., and Wright, N.A. (2000). Hepatocytes from non-hepatic adult stem cells. Nature 406, 257.

Alison, M.R., Poulsom, R., and Forbes, S.J. (2001). Update on hepatic stem cells. Liver 21, 367-373.

Alison, M.R., Poulsom, R., Otto, W.R., Vig, P., Brittan, M., Direkze, N.C., Preston, S.L., and Wright, N.A. (2003). Plastic adult stem cells: will they graduate from the school of hard knocks? J. Cell Sci. 116, 599-603.

Alison, M.R., Poulsom, R., Otto, W.R., Vig, P., Brittan, M., Direkze, N.C., Lovell, M., Fang, T.C., Preston, S.L., and Wright, N.A. (2004). Recipes for adult stem cell plasticity: fusion cuisine or readymade? J. Clin. Pathol. 57, 113-120.

Alison, M.R., Lovell, M.J., Direkze, N.C., Wright, N.A., and Poulsom, R. (2006). Stem cell plasticity and tumour formation. Eur. J. Cancer 42, 1247-1256.

Alvarez-Dolado, M., Pardal, R., Garcia-Verdugo, J.M., Fike, J.R., Lee, H.O., Pfeffer, K., Lois, C., Morrison, S.J., and VarezBuylla, A. (2003). Fusion of bone-marrow-derived cells with Purkinje neurons, cardiomyocytes and hepatocytes. Nature 425, 968-973.

Anderson, D.J., Gage, F.H., and Weissman, I.L. (2001). Can stem cells cross lineage boundaries? Nat. Med. 7, 393-395.

Arai, Y., Arai, H., Aoyagi, A., Yamagata, T., Mitani, K., Kubota, K., Kawamata, H., and Imai, Y. (2006). A solid tumor of donor cell-origin after allogeneic peripheral blood stem cell transplantation. Am. J. Transplant. 6, 3042-3043.

Avital, I., Moreira, A.L., Klimstra, D.S., Leversha, M., Papadopoulos, E.B., Brennan, M., and Downey, R.J. (2007). Donorderived human bone marrow cells contribute to solid organ cancers developing after bone marrow transplantation. Stem Cells 25, 2903-2909.

Bianchi, D.W. and Fisk, N.M. (2007). Fetomaternal cell trafficking and the stem cell debate: gender matters. J. Am. Med. Assoc. 297, 1489-1491.

Bianchi, D.W., Zickwolf, G.K., Weil, G.J., Sylvester, S., and DeMaria, M.A. (1996). Male fetal progenitor cells persist in maternal blood for as long as 27 years postpartum. Proc. Natl. Acad. Sci. USA 93, 705-708.

Bianchi, D.W., Farina, A., Weber, W., Li-Bovi, L.C., Deriso, M., Williams, J.M., and Klinger, K.W. (2001). Significant fetalmaternal hemorrhage after termination of pregnancy: implications for development of fetal cell microchimerism. Am. J. Obstet. Gynecol. 184, 703-706.

Bjornson, C.R., Rietze, R.L., Reynolds, B.A., Magli, M.C., and Vescovi, A.L. (1999). Turning brain into blood: a hematopoietic fate adopted by adult neural stem cells in vivo. Science 283, 534-537.

Blau, H.M., Brazelton, T.R., and Weimann, J.M. (2001). The evolving concept of a stem cell: entity or function? Cell 105, 829-841.
Borue, X., Lee, S., Grove, J., Herzog, E.L., Harris, R., Diflo, T., Glusac, E., Hyman, K., Theise, N.D., and Krause, D.S. (2004). Bone marrow-derived cells contribute to epithelial engraftment during wound healing. Am. J. Pathol. 165, 1767-1772.

Brazelton, T.R., Rossi, F.M., Keshet, G.I., and Blau, H.M. (2000). From marrow to brain: expression of neuronal phenotypes in adult mice. Science 290, 1775-1779.

Brittan, M., Hunt, T., Jeffery, R., Poulsom, R., Forbes, S.J., Hodivala-Dilke, K., Goldman, J., Alison, M.R., and Wright, N.A. (2002). Bone marrow derivation of pericryptal myofibroblasts in the mouse and human small intestine and colon. Gut 50 , 752-757.

Bucher, C., Stern, M., Buser, A., Heim, D., Paulussen, M., Halter, J., Tsakiris, D., Droll, A., Meyer-Monard, S., Tichelli, A., et al. (2007). Role of primacy of birth in HLA-identical sibling transplantation. Blood 110, 468-469.

Cogle, C.R., Yachnis, A.T., Laywell, E.D., Zander, D.S., Wingard, J.R., Steindler, D.A., and Scott, E.W. (2004). Bone marrow transdifferentiation in brain after transplantation: a retrospective study. Lancet 363, 1432-1437.

Collas, P. (2003). Nuclear reprogramming in cell-free extracts. Philos. Trans. R. Soc. Lond. B Biol. Sci. 358, 1389-1395.

Crain, B.J., Tran, S.D., and Mezey, E. (2005). Transplanted human bone marrow cells generate new brain cells. J. Neurol. Sci. 233, 121-123.

Doyonnas, R., LaBarge, M.A., Sacco, A., Charlton, C., and Blau, H.M. (2004). Hematopoietic contribution to skeletal muscle regeneration by myelomonocytic precursors. Proc. Natl. Acad. Sci. USA 101, 13507-13512.

Drexler, H., Meyer, G.P., and Wollert, K.C. (2006). Bone-marrowderived cell transfer after ST-elevation myocardial infarction: lessons from the BOOST trial. Nat. Clin. Pract. Cardiovasc. Med. 3 (Suppl. 1), S65-S68.

Eglitis, M.A., Dawson, D., Park, K.W., and Mouradian, M.M. (1999). Targeting of marrow-derived astrocytes to the ischemic brain. Neuroreport 10, 1289-1292.

Endler, G., Greinix, H., Winkler, K., Mitterbauer, G., and Mannhalter, C. (1999). Genetic fingerprinting in mouthwashes of patients after allogeneic bone marrow transplantation. Bone Marrow Transplant. 24, 95-98.

Evans, P.C., Lambert, N., Maloney, S., Furst, D.E., Moore, J.M., and Nelson, J.L. (1999). Long-term fetal microchimerism in peripheral blood mononuclear cell subsets in healthy women and women with scleroderma. Blood 93, 2033-2037.

Ferrari, G., Cusella-De, A.G., Coletta, M., Paolucci, E., Stornaiuolo, A., Cossu, G., and Mavilio, F. (1998). Muscle regeneration by bone marrow-derived myogenic progenitors. Science 279, 1528-1530.

Griesel, C., Heuft, H.G., Herrmann, D., Franke, A., Ladas, D., Stiehler, N., Stucki, A., Braun, M., Wollert, K.C., Meyer, G.P., et al. (2007). Good manufacturing practice-compliant validation and preparation of BM cells for the therapy of acute myocardial infarction. Cytotherapy 9, 35-43.

Grompe, M. (2003). The role of bone marrow stem cells in liver regeneration. Semin. Liver Dis. 23, 363-372.

Gussoni, E., Soneoka, Y., Strickland, C.D., Buzney, E.A., Khan, M.K., Flint, A.F., Kunkel, L.M., and Mulligan, R.C. (1999). Dystrophin expression in the $\mathrm{mdx}$ mouse restored by stem cell transplantation. Nature 401, 390-394.

Gussoni, E., Bennett, R.R., Muskiewicz, K.R., Meyerrose, T., Nolta, J.A., Gilgoff, I., Stein, J., Chan, Y.M., Lidov, H.G., Bonnemann, C.G., et al. (2002). Long-term persistence of donor nuclei in a Duchenne muscular dystrophy patient receiving bone marrow transplantation. J. Clin. Invest. 110, 807-814.

Heil, M., Ziegelhoeffer, T., Mees, B., and Schaper, W. (2004). A different outlook on the role of bone marrow stem cells in vascular growth: bone marrow delivers software not hardware. Circ. Res. 94, 573-574.

Hennessy, B., Korbling, M., and Estrov, Z. (2004). Circulating stem cells and tissue repair. Panminerva Med. 46, 1-11. 
Hong, Y.C., Liu, H.M., Chen, P.S., Chen, Y.J., Lyou, J.Y., Hu, H.Y., Yi, M.F., Lin, J.S., and Tzeng, C.H. (2007). Hair follicle: a reliable source of recipient origin after allogeneic hematopoietic stem cell transplantation. Bone Marrow Transplant. 40, 871-874.

Houghton, J., Stoicov, C., Nomura, S., Rogers, A.B., Carlson, J., Li, H., Cai, X., Fox, J.G., Goldenring, J.R., and Wang, T.C. (2004). Gastric cancer originating from bone marrow-derived cells. Science 306, 1568-1571.

Imanishi, D., Miyazaki, Y., Yamasaki, R., Sawayama, Y., Taguchi, J., Tsushima, H., Fukushima, T., Yoshida, S., Sasaki, H., Hata, T., and Tomonaga, M. (2007). Donor-derived DNA in fingernails among recipients of allogeneic hematopoietic stem-cell transplants. Blood 110, 2231-2234.

Ivanova, N.B., Dimos, J.T., Schaniel, C., Hackney, J.A., Moore, K.A., and Lemischka, I.R. (2002). A stem cell molecular signature. Science 298, 601-604.

Jiang, S., Walker, L., Afentoulis, M., Anderson, D.A., JauronMills, L., Corless, C.L., and Fleming, W.H. (2004). Transplanted human bone marrow contributes to vascular endothelium. Proc. Natl. Acad. Sci. USA 101, 16891-16896.

Korbling, M., Katz, R.L., Khanna, A., Ruifrok, A.C., Rondon, G., Albitar, M., Champlin, R.E., and Estrov, Z. (2002). Hepatocytes and epithelial cells of donor origin in recipients of peripheral-blood stem cells. N. Engl. J. Med. 346, 738-746.

Krause, D.S., Theise, N.D., Collector, M.I., Henegariu, O., Hwang, S., Gardner, R., Neutzel, S., and Sharkis, S.J. (2001). Multi-organ, multi-lineage engraftment by a single bone marrow-derived stem cell. Cell 105, 369-377.

LaBarge, M.A. and Blau, H.M. (2002). Biological progression from adult bone marrow to mononucleate muscle stem cell to multinucleate muscle fiber in response to injury. Cell 111, 589-601.

Lanzuolo, C. and Orlando, V. (2007). The function of the epigenome in cell reprogramming. Cell. Mol. Life Sci. 64, 1043-1062.

Li, B., Carey, M. and Workman, J.L. (2007). The role of chromatin during transcription. Cell 128, 707-719.

Loebinger, M.R. and Janes, S.M. (2007). Stem cells for lung disease. Chest 132, 279-285.

Masuya, M., Drake, C.J., Fleming, P.A., Reilly, C.M., Zeng, H., Hill, W.D., Martin-Studdard, A., Hess, D.C., and Ogawa, M. (2003). Hematopoietic origin of glomerular mesangial cells. Blood 101, 2215-2218.

Mathur, A. and Martin, J.F. (2004). Stem cells and repair of the heart. Lancet 364, 183-192.

Mattsson, J., Jansson, M., Wernerson, A., and Hassan, M. (2004). Lung epithelial cells and type II pneumocytes of donor origin after allogeneic hematopoietic stem cell transplantation. Transplantation 78, 154-157.

Medvinsky, A. and Smith, A. (2003). Stem cells: fusion brings down barriers. Nature 422, 823-825.

Meignin, V., Soulier, J., Brau, F., Lemann, M., Gluckman, E., Janin, A., and Socie, G. (2004). Little evidence of donorderived epithelial cells in early digestive acute graft-versushost disease. Blood 103, 360-362.

Meyer, G.P., Wollert, K.C., and Drexler, H. (2006). Stem cell therapy: a new perspective in the treatment of patients with acute myocardial infarction. Eur. J. Med. Res. 11, 439-446.

Mezey, E., Chandross, K.J., Harta, G., Maki, R.A., and McKercher, S.R. (2000). Turning blood into brain: cells bearing neuronal antigens generated in vivo from bone marrow. Science 290, 1779-1782.

Mints, M., Jansson, M., Sadeghi, B., Westgren, M., Uzunel, M., Hassan, M., and Palmblad, J. (2007). Endometrial endothelial cells are derived from donor stem cells in a bone morrow transplant recipient. Hum. Reprod. 23, 139-143.

Murata, H., Janin, A., Leboeuf, C., Soulier, J., Gluckman, E., Meignin, V., and Socie, G. (2007). Donor-derived cells and human graft-versus-host disease of the skin. Blood 109, 2663-2665.
Okamoto, R., Yajima, T., Yamazaki, M., Kanai, T., Mukai, M., Okamoto, S., Ikeda, Y., Hibi, T., Inazawa, J., and Watanabe, M. (2002). Damaged epithelia regenerated by bone marrowderived cells in the human gastrointestinal tract. Nat. Med. 8, 1011-1017.

Orlic, D., Kajstura, J., Chimenti, S., Jakoniuk, I., Anderson, S.M., Li, B., Pickel, J., McKay, R., Nadal-Ginard, B., Bodine, D.M., et al. (2001). Bone marrow cells regenerate infarcted myocardium. Nature 410, 701-705.

Palermo, A.T., LaBarge, M.A., Doyonnas, R., Pomerantz, J., and Blau, H.M. (2005). Bone marrow contribution to skeletal muscle: a physiological response to stress. Dev. Biol. 279, 336-344.

Peault, B., Oberlin, E., and Tavian, M. (2002). Emergence of hematopoietic stem cells in the human embryo. C.R. Biol. 325, 1021-1026.

Ramalho-Santos, M., Yoon, S., Matsuzaki, Y., Mulligan, R.C., and Melton, D.A. (2002).'Stemness': transcriptional profiling of embryonic and adult stem cells. Science 298, 597-600.

Reed, W., Lee, T.H., Norris, P.J., Utter, G.H., and Busch, M.P. (2007). Transfusion-associated microchimerism: a new complication of blood transfusions in severely injured patients. Semin. Hematol. 44, 24-31.

Reyes, M., Lund, T., Lenvik, T., Aguiar, D., Koodie, L., and Verfaillie, C.M. (2001). Purification and ex vivo expansion of postnatal human marrow mesodermal progenitor cells. Blood 98, 2615-2625.

Rizzino, A. (2007). A challenge for regenerative medicine: proper genetic programming, not cellular mimicry. Dev. Dyn. 236, 3199-3207.

Rovó, A., Meyer-Monard, S., Heim, D., Arber, C., Passweg, J.R., Gratwohl, A., and Tichelli, A. (2005). No evidence of plasticity in hair follicles of recipients after allogeneic hematopoietic stem cell transplantation. Exp. Hematol. 33, 909-911.

Rovó, A., Tichelli, A., Passweg, J.R., Heim, D., Meyer-Monard, S., Holzgreve, W., Gratwohl, A., and De, G.C. (2006). Spermatogenesis in long-term survivors after allogeneic hematopoietic stem cell transplantation is associated with age, time interval since transplantation, and apparently absence of chronic GvHD. Blood 108, 1100-1105.

Seifert, B., Passweg, J.R., Heim, D., Rovó, A., Meyer-Monard, S., Buechner, S., Tichelli, A., and Gratwohl, A. (2005). Complete remission of alopecia universalis after allogeneic hematopoietic stem cell transplantation. Blood 105, 426-427.

Sohn, R.L., Jain, M., and Liao, R. (2007). Adult stem cells and heart regeneration. Expert. Rev. Cardiovasc. Ther. 5, 507517.

Soldini, D., Moreno, E., Martin, V., Gratwohl, A., Marone, C., and Mazzucchelli, L. (2008). Bone-marrow-derived cells randomly contribute to neoplastic and non-neoplastic epithelial tissues. Biol. Blood Marrow Transplant., in press.

Spyridonidis, A., Schmitt-Graff, A., Tomann, T., Dwenger, A., Follo, M., Behringer, D., and Finke, J. (2004). Epithelial tissue chimerism after human hematopoietic cell transplantation is a real phenomenon. Am. J. Pathol. 164, 1147-1155.

Stamm, C., Westphal, B., Kleine, H.D., Petzsch, M., Kittner, C., Klinge, H., Schumichen, C., Nienaber, C.A., Freund, M., and Steinhoff, G. (2003). Autologous bone-marrow stem-cell transplantation for myocardial regeneration. Lancet 361, 4546.

Stamm, C., Kleine, H.D., Westphal, B., Petzsch, M., Kittner, C., Nienaber, C.A., Freund, M., and Steinhoff, G. (2004). CABG and bone marrow stem cell transplantation after myocardial infarction. Thorac. Cardiovasc. Surg. 52, 152-158.

Suratt, B.T., Cool, C.D., Serls, A.E., Chen, L., Varella-Garcia, M., Shpall, E.J., Brown, K.K., and Worthen, G.S. (2003). Human pulmonary chimerism after hematopoietic stem cell transplantation. Am. J. Respir. Crit. Care Med. 168, 318-322.

Suzuki, T., Nishida, M., Futami, S., Fukino, K., Amaki, T., Aizawa, K., Chiba, S., Hirai, H., Maekawa, K., and Nagai, R. (2003). Neoendothelialization after peripheral blood stem cell trans- 
plantation in humans: a case report of a Tokaimura nuclear accident victim. Cardiovasc. Res. 58, 487-492.

Tada, M., Takahama, Y., Abe, K., Nakatsuji, N., and Tada, T. (2001). Nuclear reprogramming of somatic cells by in vitro hybridization with ES cells. Curr. Biol. 11, 1553-1558.

Takahashi, K., Tanabe, K., Ohnuki, M., Narita, M., Ichisaka, T., Tomoda, K., and Yamanaka, S. (2007). Induction of pluripotent stem cells from adult human fibroblasts by defined factors. Cell 131, 861-872.

Terada, N., Hamazaki, T., Oka, M., Hoki, M., Mastalerz, D.M., Nakano, Y., Meyer, E.M., Morel, L., Petersen, B.E., and Scott, E.W. (2002). Bone marrow cells adopt the phenotype of other cells by spontaneous cell fusion. Nature 416, 542-545.

Theise, N.D., Nimmakayalu, M., Gardner, R., Illei, P.B., Morgan, G., Teperman, L., Henegariu, O., and Krause, D.S. (2000). Liver from bone marrow in humans. Hepatology 32, 11-16.

Thiede, C. (2004). Diagnostic chimerism analysis after allogeneic stem cell transplantation: new methods and markers. Am. J. Pharmacogenom. 4, 177-187.

Thiede, C., Florek, M., Bornhauser, M., Ritter, M., Mohr, B., Brendel, C., Ehninger, G., and Neubauer, A. (1999). Rapid quantification of mixed chimerism using multiplex amplification of short tandem repeat markers and fluorescence detection. Bone Marrow Transplant. 23, 1055-1060.

Thiede, C., Prange-Krex, G., Freiberg-Richter, J., Bornhauser, M., and Ehninger, G. (2000). Buccal swabs but not mouthwash samples can be used to obtain pretransplant DNA fingerprints from recipients of allogeneic bone marrow transplants. Bone Marrow Transplant. 25, 575-577.

Thiede, C., Bornhauser, M., Oelschlagel, U., Brendel, C., Leo, R., Daxberger, H., Mohr, B., Florek, M., Kroschinsky, F., Geissler, G., et al. (2001). Sequential monitoring of chimerism and detection of minimal residual disease after allogeneic blood stem cell transplantation (BSCT) using multiplex PCR amplification of short tandem repeat-markers. Leukemia 15, 293-302.

Thiede, C., Bornhauser, M., and Ehninger, G. (2004). Evaluation of STR informativity for chimerism testing - comparative analysis of 27 STR systems in 203 matched related donor recipient pairs. Leukemia 18, 248-254.

Tran, S.D., Pillemer, S.R., Dutra, A., Barrett, A.J., Brownstein, M.J., Key, S., Pak, E., Leakan, R.A., Kingman, A., Yamada, K.M., et al. (2003). Differentiation of human bone marrowderived cells into buccal epithelial cells in vivo: a molecular analytical study. Lancet 361, 1084-1088.

Tse, H.F., Kwong, Y.L., Chan, J.K., Lo, G., Ho, C.L., and Lau, C.P. (2003). Angiogenesis in ischaemic myocardium by intramyocardial autologous bone marrow mononuclear cell implantation. Lancet 361, 47-49.

Vassilopoulos, G., Wang, P.R., and Russell, D.W. (2003). Transplanted bone marrow regenerates liver by cell fusion. Nature 422, 901-904.

Wang, X., Willenbring, H., Akkari, Y., Torimaru, Y., Foster, M., AlDhalimy, M., Lagasse, E., Finegold, M., Olson, S., and Grompe, M. (2003). Cell fusion is the principal source of bone-marrow-derived hepatocytes. Nature 422, 897-901.

Weimann, J.M., Charlton, C.A., Brazelton, T.R., Hackman, R.C., and Blau, H.M. (2003a). Contribution of transplanted bone marrow cells to Purkinje neurons in human adult brains. Proc. Natl. Acad. Sci. USA 100, 2088-2093.

Weimann, J.M., Johansson, C.B., Trejo, A., and Blau, H.M. (2003b). Stable reprogrammed heterokaryons form spontaneously in Purkinje neurons after bone marrow transplant. Nat. Cell Biol. 5, 959-966.

Wollert, K.C., Meyer, G.P., Lotz, J., Ringes-Lichtenberg, S., Lippolt, P., Breidenbach, C., Fichtner, S., Korte, T., Hornig, B., Messinger, D., et al. (2004). Intracoronary autologous bonemarrow cell transfer after myocardial infarction: the BOOST randomised controlled clinical trial. Lancet 364, 141-148.

Woodbury, D., Schwarz, E.J., Prockop, D.J., and Black, I.B. (2000). Adult rat and human bone marrow stromal cells differentiate into neurons. J. Neurosci. Res. 61, 364-370.

Ying, Q.L., Nichols, J., Evans, E.P., and Smith, A.G. (2002). Changing potency by spontaneous fusion. Nature 416 , 545-548. 